\title{
An Analytical Formulation of Stress-Block Parameters for Confined Con- crete
}

\author{
Franco Braga, Rosario Gigliotti, Michelangelo Laterza* and Michele D’Amato
}

Department of Structural and Geotechnical Engineering, University of Rome, La Sapienza, Italy; Department of Structural Engineering, University of Basilicata, Potenza, Italy

\begin{abstract}
In order to evaluate the capacity of RC members, the main codes allow the use of stress-strain laws that can reproduce closely the real behaviour of concrete, as opposed to parabola-rectangular or equivalent rectangular diagrams. Both sectional strength and ductility depend on the law of concrete, therefore they are influenced by the confinement of members, as evidenced in the literature. In this paper a possible design approach is presented, based on classic section analysis methods. The method uses parameters that represent the stress-strain law of confined concrete. The studies carried out show that such parameters can be chosen through simple relationships depending on the strength of non-confined concrete, on the amount and geometry of longitudinal and transverse reinforcement, and on the geometry of the section. At this aim some numerical analyses have been performed using an analytical model of confined concrete, capable of taking into account all the mentioned effects, even in the case of various sources of confinement, when different types of hoops and external elements (FRP wrappings, steel plates, etc.) are used. More in detail, the section interaction diagrams for the different limit states requires the definition of an appropriate upper bound for the strain of concrete. Therefore the study focuses on the possibility of using stress-blocks depending on the maximum stain assumed, or on the level of residual stress accepted in concrete according to a specified limit state. Further studies will extend the parametric analysis in order to obtain design equations to be implemented in codes.
\end{abstract}

\section{INTRODUCTION}

In the last years the main design codes have adopted the performance approach. By considering the important limit states, this approach defines the performance level requested to the overall structure and its members.

Referring to the RC structures, the main researches regard the modelling of materials and members, and the development of the finite elements (for non linear analysis) capable to describe the non-linear phenomena.

It is well known that the RC buildings behaviour is essentially due to the flexural response of the members and their axial load level.

Neozeland Design Code 3101 (1995) [1] and Eurocode 8 (EC8) [2] link the transversal reinforcement bars to the global and local ductility behaviour.

The transversal reinforcement contributes to better the structural ductility. This for two reasons: it impedes the buckling of longitudinal bars when the section reaches high curvatures and modifies the concrete stress-strain relationship increasing strength and ductility. In this way we have an increasing of section curvature and consequently of global ductility.

For these reasons the confinement of the concrete has a very important role in structural engineering, and in recent years it regards strengthening of the existing buildings, too.

*Address correspondence to this author at the Department of Structural Engineering, University of Basilicata, Potenza, Italy;

E-mail: michelangelo.laterza@unibas.it
In order to evaluate the capacity of the RC cross-sections, the main codes allow to use simplified relationships for concrete under compression (parabola-rectangle and equivalent rectangular distribution, also called stress-block). As an alternative, Eurocode 2 (EC2) [3], ACI 318 [4] and NZS 4203 [5] allow to use stress-strain laws that reproduce closely the real behaviour of the compressive concrete.

According to previous researches about compressive concrete, this paper has the aim to provide a first approach to evaluate the capacity of RC sections by the use of stressblocks for confined concrete.

An analytical evaluation was carried out using a model that estimates analytically the confinement effects on the core concrete. By considering the interaction between concrete and transversal/longitudinal bars and/or transversal strengthening (as FRP), this model provides a global parameter called "equivalent confining pressure" that allows us to evaluate the stress-strain relationship for confined concrete.

Moreover, analysis have been made supposing plain section remains plane after bending, strain in bounded reinforcement bar is the same as that in the surrounding concrete, tensile strength of concrete is neglected.

The results have allowed to propose a first formulation of stress-block parameters (depending to materials strength, section geometry and confinement level) to use within the $\mathrm{RC}$ section equilibria.

It has been also investigated the influence of compressive concrete maximum strain on the capacity of the section. 


\section{FLEXURAL STRENGTH OF RC SECTION}

In order to evaluate the RC section capacity, the following classical assumptions are made:

- non-linear constitutive laws for materials. The maximum strains assumed depend by the state limit considered.

- plain section remains plane after bending;

- the strain in bonded reinforcement is the same as that in the surrounding concrete;

- concrete tensile strength is neglected (for all limit states where concrete is cracked).

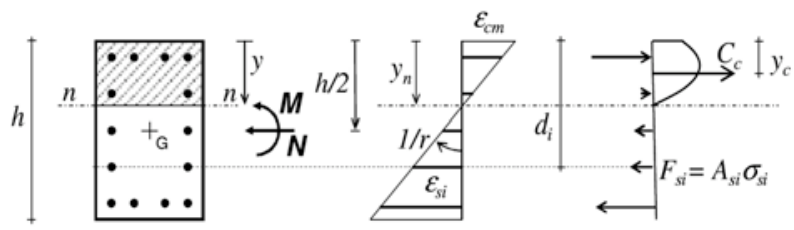

Fig. (1). Stress and strain diagrams along the section.

For each deformation profile fixed along cross section, the M-N couple in balance with internal forces is described by:

$N=C_{c}+\sum_{i=1}^{n} A_{s i} \sigma_{s i}$

$M=C_{C} \cdot\left(\frac{h}{2}-y_{C}\right)+\sum_{i=1}^{n}\left[A_{s i} \sigma_{s i}\left(d_{i}-\frac{h}{2}\right)\right]$

\section{STRESS-BLOCKS}

In previous equations instead of real $\sigma-\varepsilon$, it is allowed the use of a rectangular equivalent diagram for compressive concrete called stress-block.

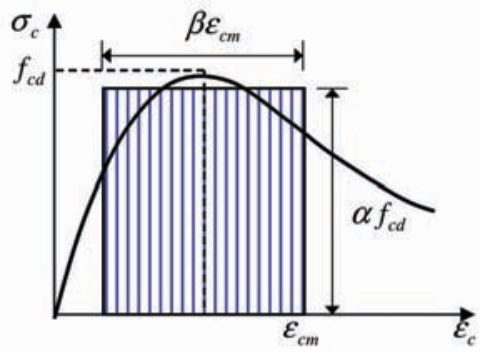

Fig. (2). Stress-strain relationship for concrete and equivalent rectangular diagram.

By fixing the maximum concrete strain $\varepsilon_{\mathrm{cm}}$, the stressblock is described through the effective strength $\alpha f_{\mathrm{cd}}$ and the effective height of compression zone $\beta \varepsilon_{\mathrm{cm}}$. These parameters are given by:

$$
\begin{aligned}
& \int_{0}^{\varepsilon_{c m}} \sigma_{c} d \varepsilon_{c}=\alpha f_{c d} \cdot \beta \varepsilon_{c m} \\
& \int_{0}^{\varepsilon_{c m}} \sigma_{c} \varepsilon_{c} d \varepsilon_{c}=\alpha f_{c d} \cdot \beta \varepsilon_{c m} \cdot(1-0,5 \beta) \varepsilon_{c m}
\end{aligned}
$$

Referring to unconfined concrete, EC2 permits to use either a parabola-rectangular or a simplified diagram as the rectangular equivalent one, whose parameters are given as a function of concrete strength (Fig. 3).
The EC2 also furnishes the stress-strain relationship for confined concrete and its ultimate strain, but does not indicate the upper limit for each limit state.

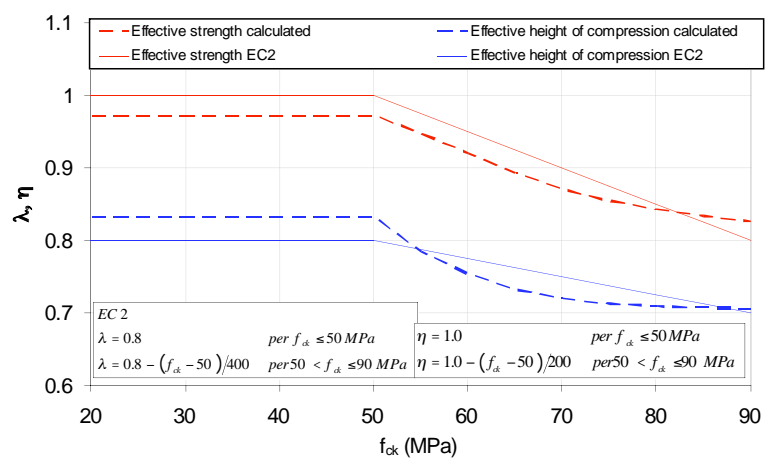

Fig. (3). Stress-block parameters of unconfined concrete in according to EC2.

The Fig. (4) shows stress-blocks adopted by some national codes [1-9].
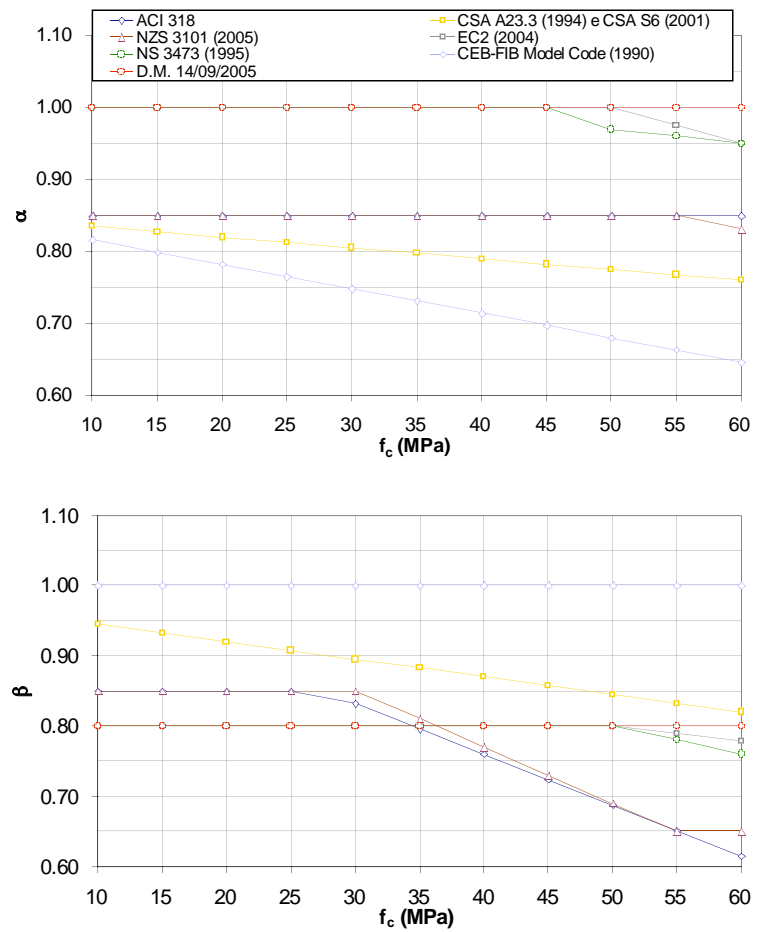

Fig. (4). Stress-block parameters furnished by some national codes.

As the EC2, the ACI 318, NZS 3101 (1995) and Italian code D.M. 14/09/2005 [6] too, allow to use $\sigma-\varepsilon$ diagram which can reproduce more closely the real behaviour of concrete.

\section{ANALYTICAL MODEL USED FOR CONFINED CONCRETE}

To obtain stress-block parameters for confined concrete, numerical analyses have been made using a completely analytical model of confined concrete, proposed by three of the authors of the present paper (Braga, Gigliotti and Laterza [10]). 
The key assumption of the model is that the increment of stress in the concrete section is produced without any out-ofplane strain. This means that the confinement exercised by the transverse reinforcements should take place in plane strain conditions.

In general terms, referring to a generically representative cross section, the stress-strain relationship for concrete can be written as follows:

$$
\sigma_{Z}\left(\varepsilon_{Z}\right)=\sigma_{Z 0}\left(\varepsilon_{Z}\right)+\Delta \sigma_{Z}\left(\varepsilon_{Z}\right)
$$

where $\sigma_{z}\left(\varepsilon_{z}\right)$ and $\sigma_{z 0}\left(\varepsilon_{z}\right)$ are the stress of confined and unconfined concrete, respectly; $\varepsilon_{z}$ is the related strain. $\Delta \sigma_{z}\left(\varepsilon_{z}\right)$ is the strength increment related to the triaxial state. This increment is proportional to confining pressures, caused by the transverse reinforcements and their distribution, to the characteristics and to the structural element dimensions.

With reference to the previous hypothesis, the strength increment $\Delta \sigma_{z}\left(\varepsilon_{z}\right)$ due to confinement is constant inside the section, and is given by:

$$
\Delta \sigma_{Z}=2 v B l^{2}
$$

where

$$
\begin{aligned}
\mathrm{B} & =\frac{18 E_{c} E_{s} A_{s} v\left[S E_{c} l^{3}+105 E_{s} I_{s}(v+1)\right] \cdot \varepsilon_{z}}{l^{2}\left\{25 S^{2} E_{c}^{2} l^{4}+6 S E_{c} E_{s} l \cdot C^{\prime}-1890 E_{s}^{2} I_{s} A_{s}\left(v^{2}-1\right)\right\}} \\
C^{\prime} & =315 I_{s}(v+1)+2 l^{2} A_{s}(2 v+5)
\end{aligned}
$$

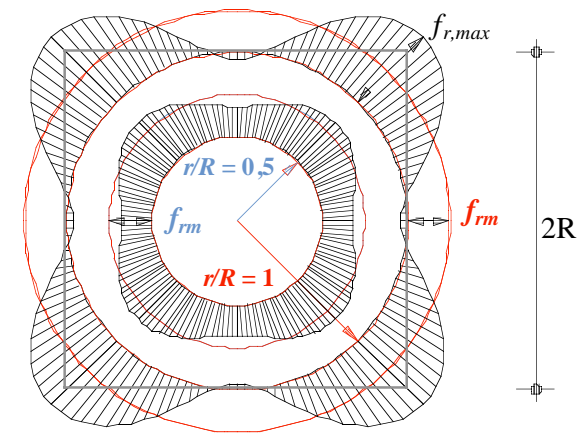

Fig. (5). Confining pressure along internal circumferences.

Fig. (5) shows, in polar coordinates, the confinement pressure.

On cylinders internal to section (square or circular), the mean confining pressure $f_{r m}$ is given by:

$$
f_{r m}=-B l^{2}
$$

and substituting into Eq. (6):

$$
\Delta \sigma_{z}\left(f_{r}, \tau_{n m}\right)=\Delta \sigma_{z}=-2 v f_{r m}=\Delta \sigma_{z}\left(f_{r m}\right)
$$

The $f_{r m}$ pressure is a constant varying the radius of cylinders. Therefore, this parameter is appropriate to describe in every point the confining state inside the section. $\mathrm{f}_{\mathrm{rm}}$ is also called "equivalent confining pressure".

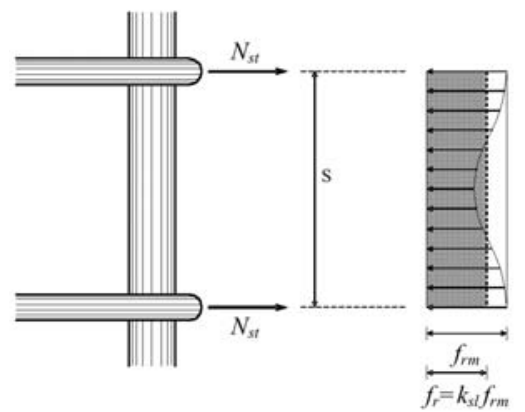

Fig. (6). Distribution of vertical confining pressures.

The model takes into account the distribution of confining pressures offered by longitudinal reinforcements (Fig. 6).

By assuming that the pressures distributed along the structural element are uniform, the confining pressure $f_{r m}$ is reduced by the following parameter:

$$
k_{s l}=\frac{45 \xi_{l}^{3}}{45 \xi_{l}^{3}+\beta \xi_{s t}}
$$

where $\xi_{l}=\frac{\phi_{l o n}}{S} ; \beta=\frac{\phi_{s t}}{\phi_{l o n}} ; \xi_{s t}=\frac{\phi_{s t}}{l}$

when the bending stiffness of longitudinal bars becomes negligible, only the arching action between two stirrups spreads the confining pressures along the column. Thus, it can be assumed that $k_{s l} \geq k_{c}$, where $\mathrm{k}_{\mathrm{c}}$ is given by the relationship (Sheikh and Uzumeri, 1980) [11]:

$$
k_{c}=\left(1-\frac{S}{4 l_{s t}}\right)^{2}
$$

The effective confining pressure due to square stirrups becomes:

$$
f_{r}=k_{s l} f_{r m}
$$

By using the analytical formulation of the confining pressures obtained for square section and/or circular sections with a single stirrup ( $\mathrm{S} 1$ and/or C configurations), the pressures applied by other highly complex configurations of transverse reinforcements can also be obtained. In such cases, in order to calculate the confining pressure $f_{r}$, the principle of superposition is used and applied to the pressures $f_{r s}$ calculated for each stirrup and/or FRP/Steel wrapping (Figs. 7-8).
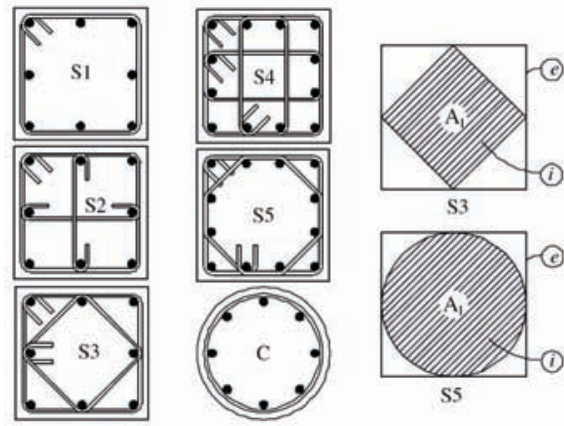

Fig. (7). Square and circular reinforcement configurations. 

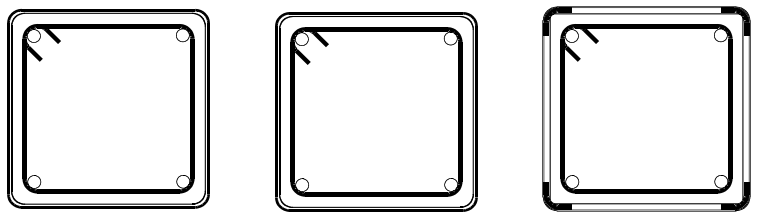

Fig. (8). External jackets (FRP and Steel).

For example, for the sections confined by internal and external stirrup (Fig. 9), the confining pressure is given by:

$f_{r}=\frac{A_{1}}{A_{e}} f_{r i}+f_{r e}$

Referring S4 section (Fig. 9), $\mathrm{f}_{\mathrm{r}}$ is obtained by:

(a) $f_{r}=\left(1+\frac{b}{L}\right) f_{r 1}+\frac{b}{L} f_{r 2}$

(b) $f_{r}=f_{r L}+\frac{2 b}{L} f_{r 2}$

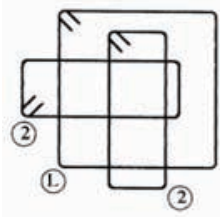

(b)

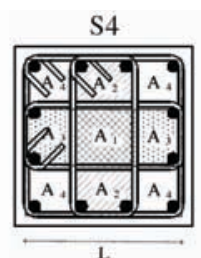

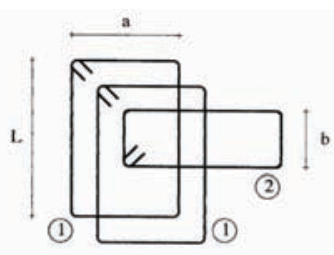

(a)
Fig. (9). Section S4.

As examples, consecutively stress-strain relationships are plotted and evaluated for two analyzed cases. Figures also show the confining pressures (as a function of longitudinal strain of concrete) separately applied by internal and external reinforcements and the resultant confining pressure $f_{\mathrm{rm}}$.
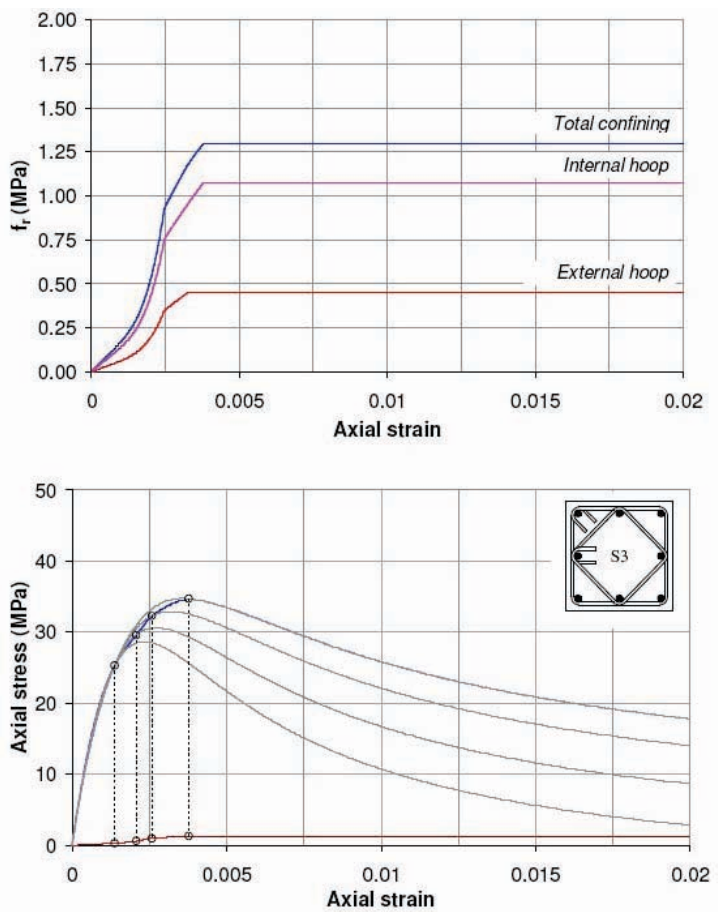

Fig. (10). S3 section type. Confining pressures and stress-strain relationship.
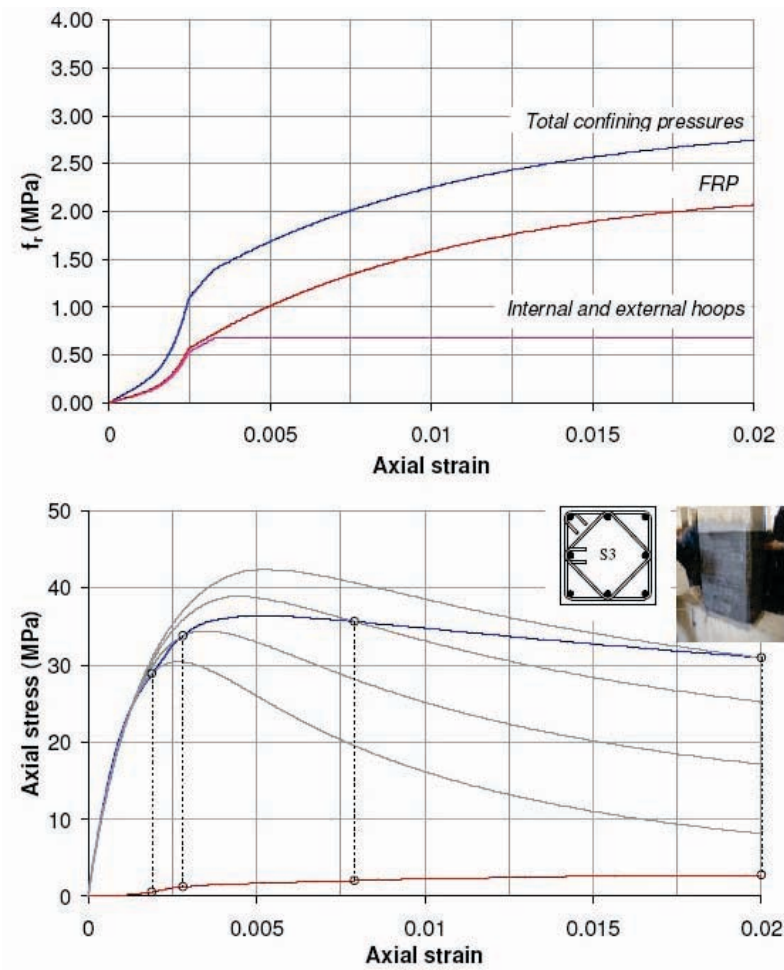

Fig. (11). S3 section type with strengthened by FRP Confining pressures and stress-strain relationship.

For S3 section type, it can be observed that the confining pressure remains constant beyond the point corresponding to the yielding stress of steel.

Instead, the result confining pressure due to FRP increases after the yielding of internal stirrup until wrapping failure occurs.

\section{FLEXURAL STRENGTH OF RC CONFINED SEC- TION}

For studying the confined section are requested two different laws for the concrete: a confined $\sigma-\varepsilon$ for core and an unconfined one for cover.
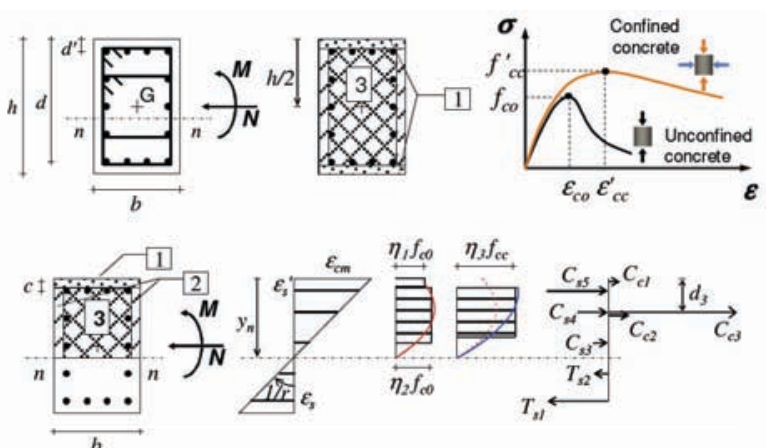

Fig. (12). Confined section: stress diagrams and internal forces.

The M-N interaction curve, for each limit state, is obtained fixing the material longitudinal strains and turning the strain profile around them. By referring to Ultimate Limit State (ULS), Fig. (13) shows the deformation fields and M-N interaction curve in according to EC2.

In general, the upper limits for material deformations depend on the performance requirements. 


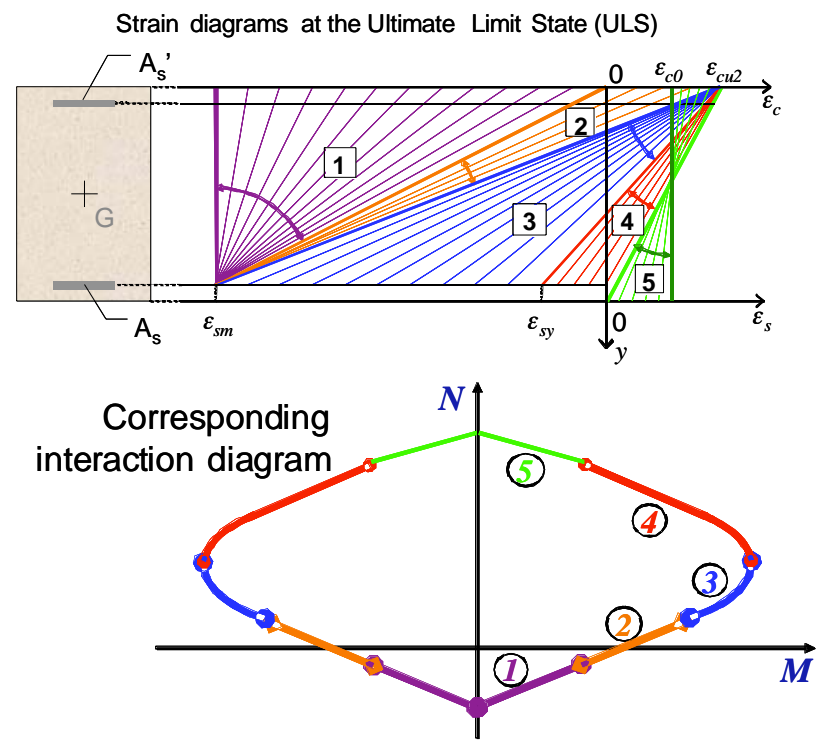

Fig. (13). Strain diagrams and interaction curve in according to Eurocode2.

By referring to ULS, the EC2 and D.M. 14/09/2005 assume for strain compressive concrete the limit of $3,5 \%$ o. Instead, this limit is equal to $3 \%$ for ACI 318 and NZS 3101 (2005). As shown in previous experimental tests these limits are referred to unconfined concrete sections [12].

To analytically evaluate the influence of maximum deformation assumed on section strength, it has been utilized the software Response2000 [13] .

This software puts no limit to the maximum material deformations. Once fixed the axial load N, it researches the strain profile to which the maximum flexural strength corresponds.

The analysis have been made referring to a square section $(\mathrm{L}=500 \mathrm{~mm}$ ) and using four $\sigma-\varepsilon$ relationships for concrete, obtained from unconfined concrete strength $\left(\mathrm{f}_{\mathrm{c} 0}=30 \mathrm{MPa}\right)$ by different confinement levels (Fig. 14).

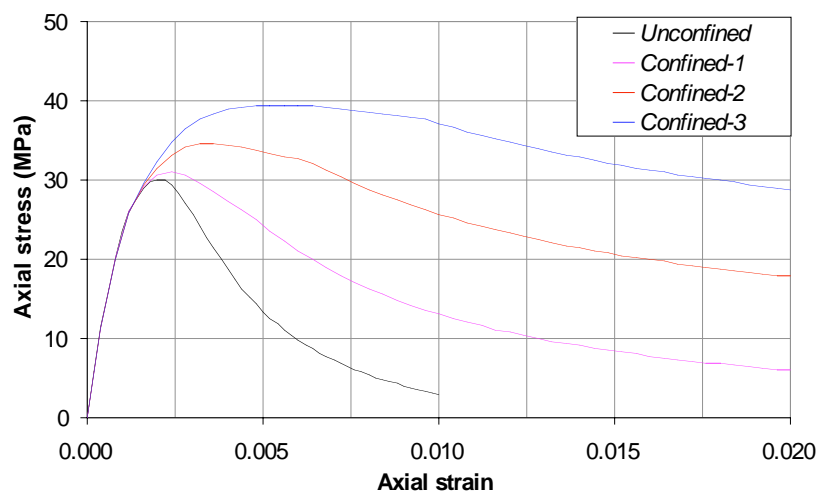

Fig. (14). Stress-strain relationships considered.

Three different amount of longitudinal bars have been considered (minimum, medium, maximum according to EC8).
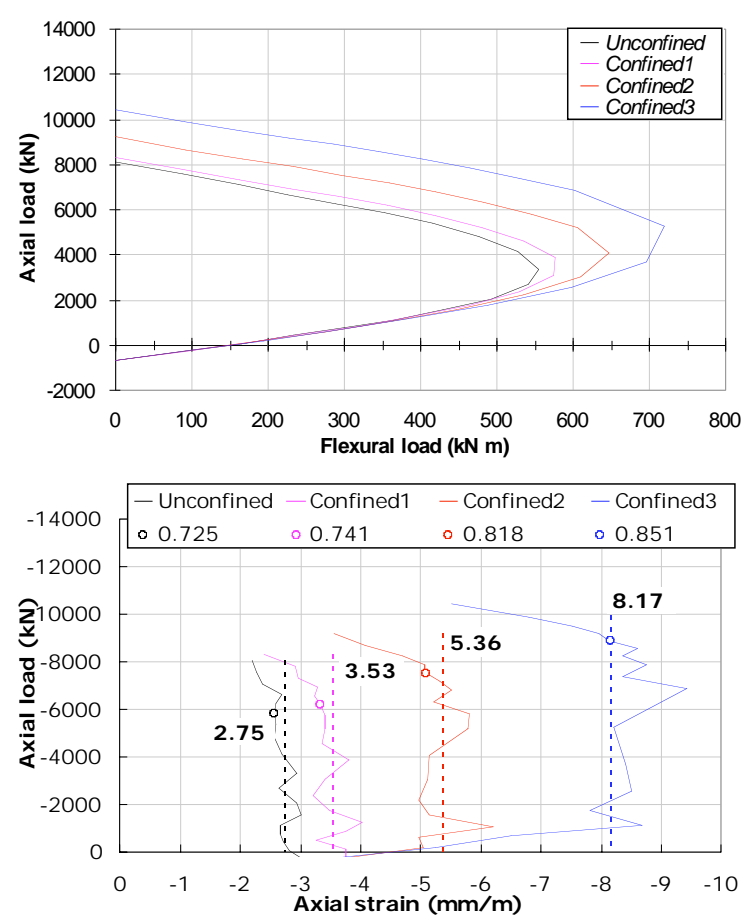

Fig. (15). Interaction curves and maximum longitudinal strains of concrete referred to mean amount of longitudinal bars.
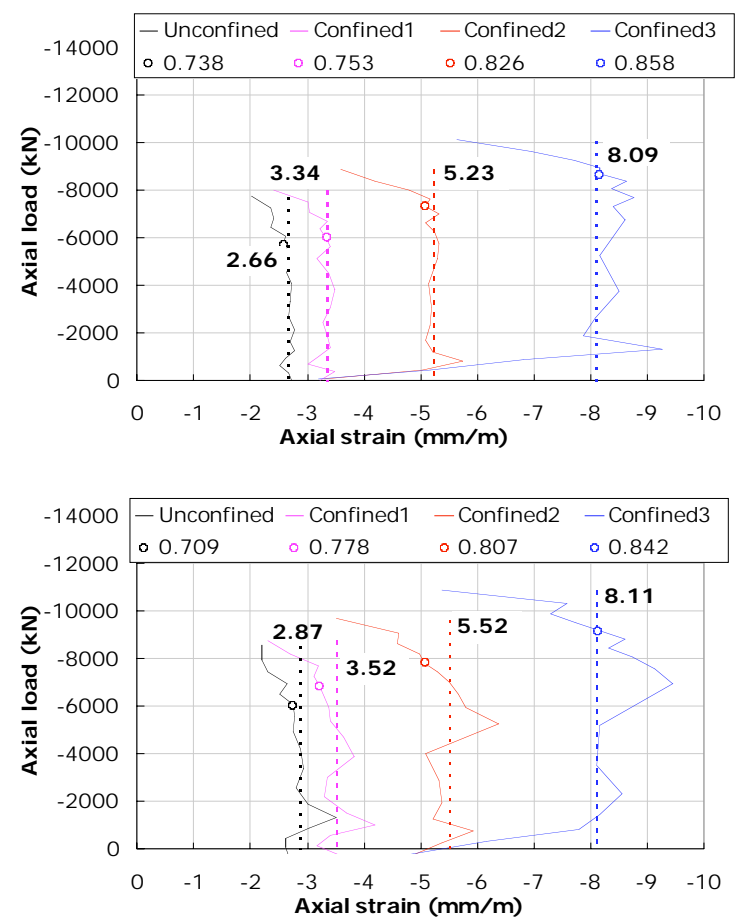

Fig. (16). Maximum longitudinal strains of concrete referred to minimum and maximum amount of longitudinal bars.

The preliminary study shows that:

- for each case analyzed, the strain $\varepsilon_{\mathrm{cm}}$ corresponding to maximum section strength is constant in a wide range of axial force $\mathrm{N}$; 
- $\varepsilon_{\mathrm{cm}}$ increases with increasing of level confinement inside the section and it results nearly independent from the longitudinal bars percentage;

- unconfined concrete $\varepsilon_{\mathrm{cm}}$ is close by the maximum strain values adopted by some codes for the ULS. In particular, this value is equal to the $3,5 \%$ according to EC2 and to the $3 \%$ for the ACI 318 and NZS 3101 (2005).

As an alternative, the interaction curves can be obtained by "conventional method", which requests the definition of material maximum strains. In this way, $\varepsilon_{\mathrm{cm}}$ of concrete can be fixed by the ratio:

$\gamma=f_{c m} / f_{c c}$

where $f_{c c}$ is the peak of confined stress-strain curve, while $f_{c m}$ corresponds to $\varepsilon_{\mathrm{cm}}$ considerated.

Next figures (Figs. 17-20) show convectional interaction curves obtained considering different $\gamma$ values.

By using the "conventional method", the interaction curve which is associated the maximum flexural strength of RC section (Response2000 curves) is obtained, too. However, the appropriate $\gamma$ value is variable in the cases considered.

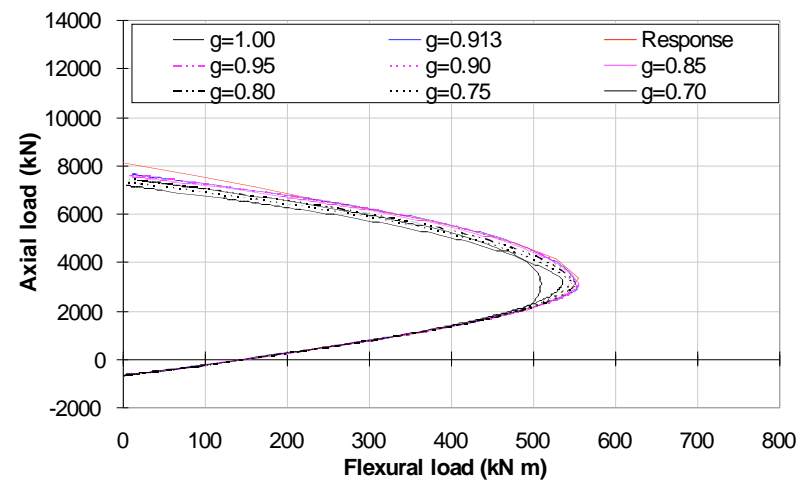

Fig. (17). Interaction curves obtained varying the maximum concrete strain (unconfined concrete and mean amount of longitudinal bars).

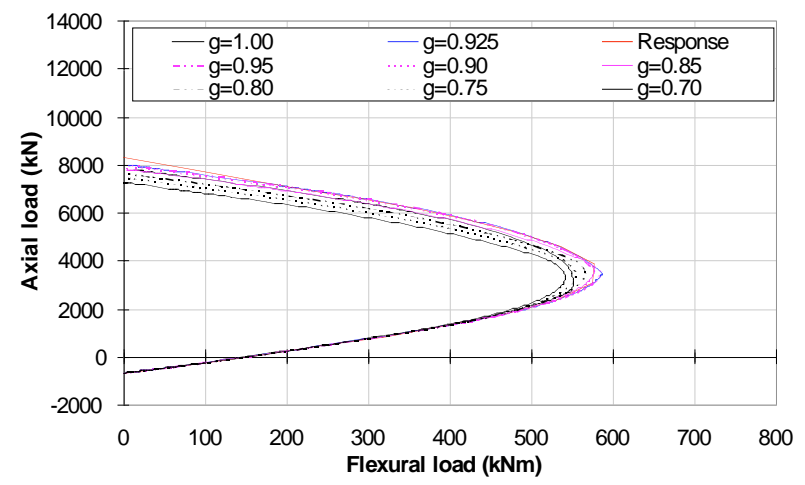

Fig. (18). Interaction curves obtained varying the maximum concrete strain (Confinedl concrete and mean amount of longitudinal bars).

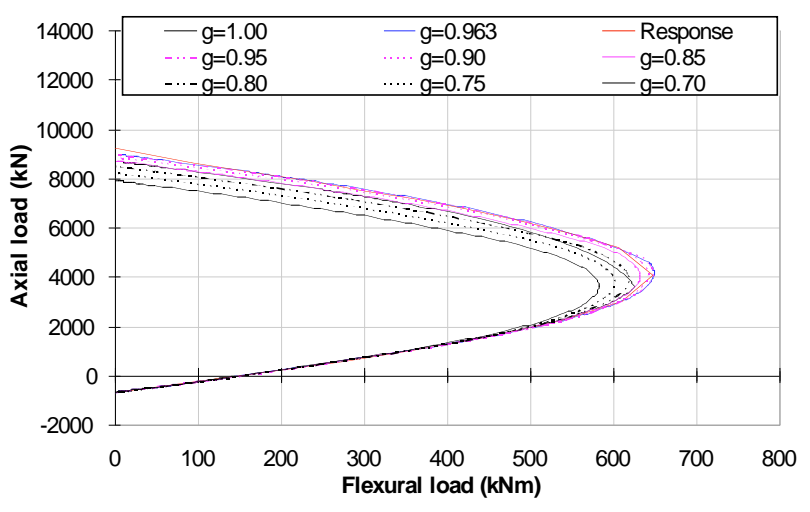

Fig. (19). Interaction curves obtained varying the maximum concrete strain (Confined 2 concrete and mean amount of longitudinal bars).

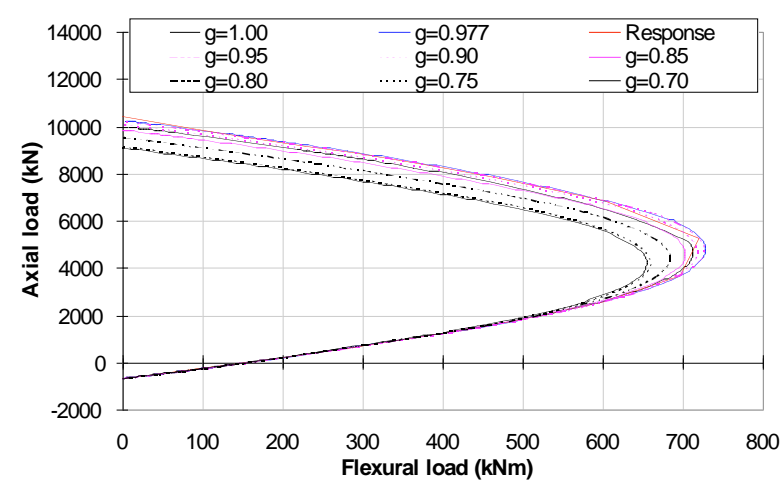

Fig. (20). Interaction curves obtained varying the maximum concrete strain (Confined 3 concrete and mean amount of longitudinal bars).
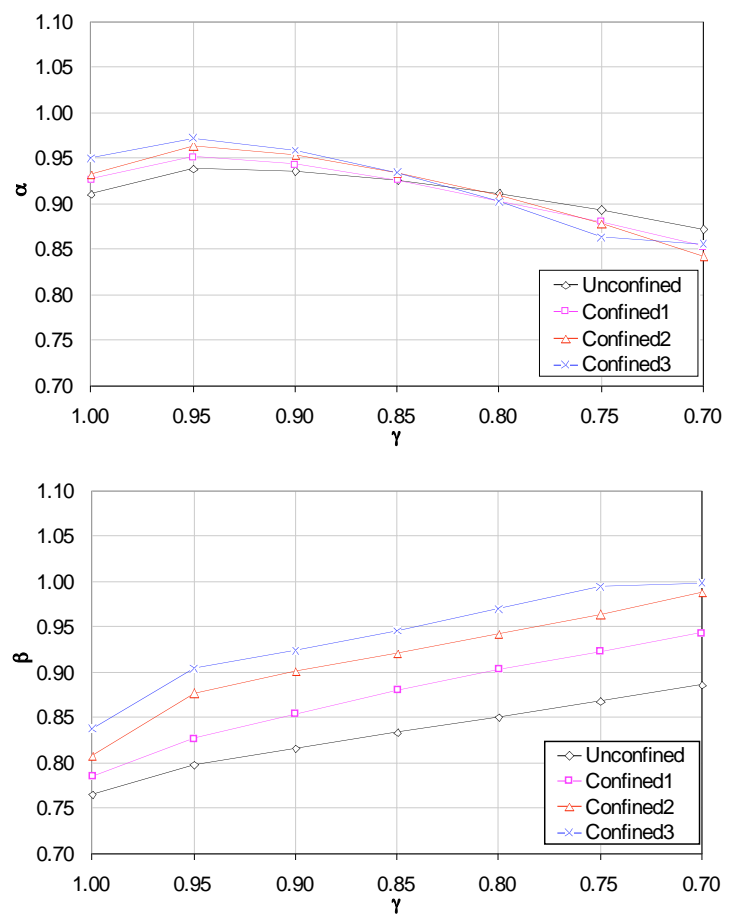

Fig. (21). $\alpha$ and $\beta$ parameters relative to the analysis considered. 
It can be also observed that the section capacity tends to decrease if $\varepsilon_{\mathrm{cm}}$ increases.

In all cases considered the maximum strain of concrete is more than $3 \%$ or $3,5 \%$. Such values are, on the contrary, close to unconfined cases, as numerical analysis have shown.

Fig. (21) shows $\alpha$ and $\beta$ stress-block parameters obtained, as a function of $\gamma$.

\section{EVALUATION OF STRESS-BLOCK PARAMETERS}

As previously reported, main codes allow to use stressstrain relationship that reproduces closely the real behaviour of confined concrete. However, they do not furnish both stress-block parameters and upper limit for strain of compressive concrete for each limit state.

Moreover, main codes utilize the volumetric ratio of confining reinforcement as a parameter which indicates the confinement level along the $\mathrm{RC}$ member.

However, as Fig. (22) shows, the geometrical volumetric ratio of confining reinforcement $\rho_{\mathrm{s}}$ is not appropriated to indicate the confinement level along the column. Infact, it is not the same for the different types of transversal reinforcement even if $\rho_{\mathrm{s}}$ is a constant in all cases considered.
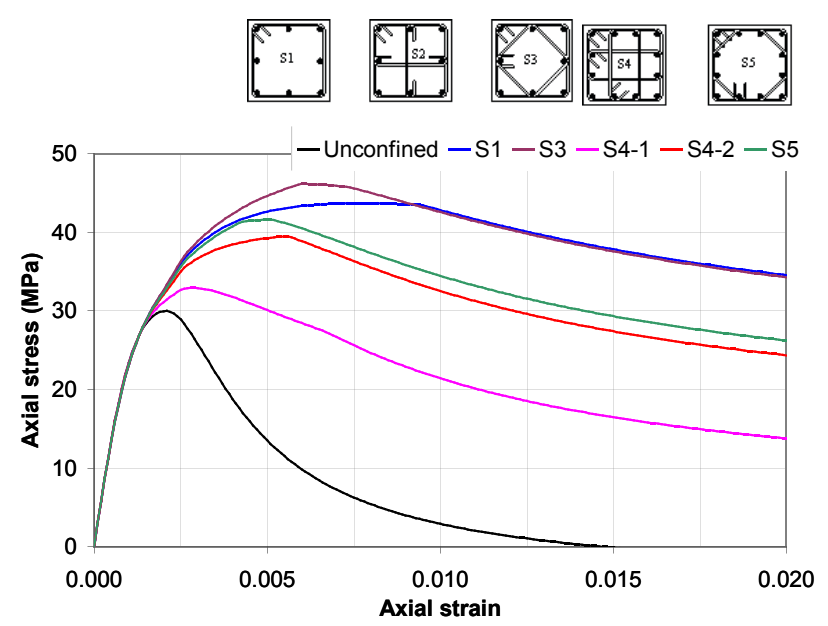

Fig. (22). Stress-strain relationship of concrete for different types of reinforced section. $\left(\rho=0.02, \mathrm{~L}=500 \mathrm{~mm}, \phi_{\mathrm{l}}=12 \mathrm{~mm}, \phi_{\mathrm{tr}}=8 \mathrm{~mm}\right.$, $\left.\mathrm{f}_{\mathrm{c} 0}=30 \mathrm{MPa}, \mathrm{f}_{\mathrm{y}}=430 \mathrm{MPa}\right)$.

In order to obtain a first analytical formulation of stressblock parameters for confined concrete, analytical analysis were carried out. Three different values of unconfined concrete strength $\mathrm{f}_{\mathrm{c} 0}(20,30,40 \mathrm{MPa})$ and three different of lateral tie length $\mathrm{L}(300,400,500 \mathrm{~mm})$ have been considered. Stress-block parameters obtained are reported as a function of transversal reinforcement spacing $S$ and of maximum concrete strain $\varepsilon_{\mathrm{cm}}$ by $\gamma$ parameter.

\section{$\alpha$ parameter}

In Fig. (23) are plotted $\alpha$ values of all the analyzed cases. It can be observed that for each $\gamma$ value considered the results are less scattered around medium value, unless for $\gamma$ less than 0,75 .

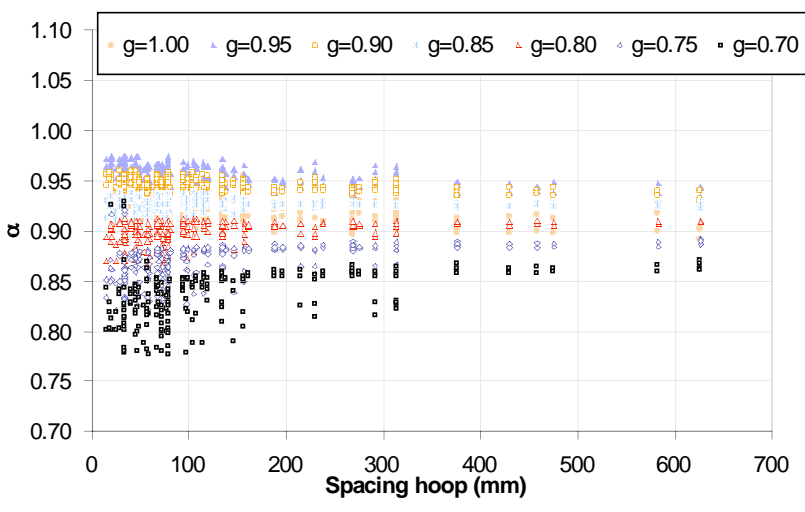

Fig. (23). Variation of $\alpha$ parameter with spacing hoop for various $\gamma$ values.

Fig. (24) shows three curves referred to the smallest, the medium and the biggest $\alpha$ values obtained as a function of $\gamma$.

According to the results, it could propose the following expression for $\alpha$ :

$\alpha=0,05+\gamma \leq 0,9$

The effective strength $\alpha f_{c c}$ is given by:

$f_{c c-S B}=\alpha f_{c c}=\alpha k_{s} f_{c 0}=\alpha k_{s} k_{c} f_{c}^{\prime}$

where

$f_{c 0}$ is the unconfined concrete strength

$k_{s}$ is the ratio of confined concrete strength $\mathrm{f}_{\mathrm{cc}}$ to unconfined concrete strength $\mathrm{f}_{\mathrm{c} 0}$

$k_{c}$ is the ratio of the column compressive strength $\left(\mathrm{f}_{\mathrm{c} 0}\right)$ to the cylindrical specimen strength (f' $)$ ). For the ULS, Sheik et $A l$. (1990) [14] have proposed for $\mathrm{k}_{\mathrm{c}}$ the following values:

$\left.\begin{array}{ll}k_{c}=0,85 & \operatorname{per} N=N_{0} \\ k_{c}=1 & \operatorname{per} N \leq N_{b}\end{array}\right\}$

with a linear interpolation for intermediate cases. In the previous relations, $\mathrm{N}$ is the axial load applied, and $\mathrm{N}_{\mathrm{b}}$ is the balanced axial load.

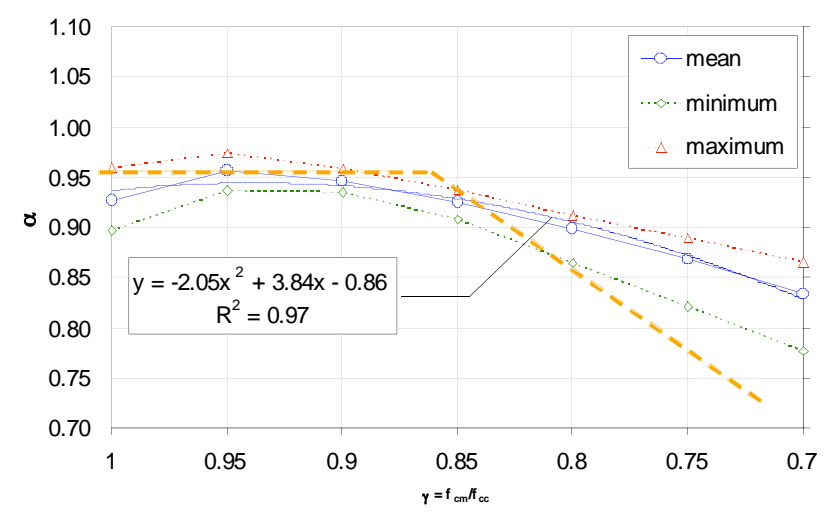

Fig. (24). $\alpha$ parameter: minimum, mean and maximum value for each $\gamma$ considered.

For $\mathrm{N}=\mathrm{N}_{0} \alpha$ is equal to 1 , while as shown by obtained results, for $\gamma=0.9-0.95$ (corresponding to the maximum flexural 
strength of the section) $\alpha$ assumes a value next to 0.9 . Therefore it could propose:

$\left.\begin{array}{c}\alpha_{S L U}^{*}=\alpha \cdot k_{c}=0,85 \operatorname{per} N=N_{0} \\ \alpha_{S L U}^{*}=\alpha \cdot k_{c}=0,9 \operatorname{per} N \leq N_{b}\end{array}\right\}$

Finally, for ULS we assume only one value for a $\mathrm{k}_{\mathrm{c}}$ equal to 0.85 which is the same for main international codes.

In general, for the different limit states, the strength $\alpha f_{c c}$ of stress block could be expressed as shown:

$$
f_{c c-S B}=\alpha f_{c c}=\alpha^{*} k_{s} f_{c}^{\prime}
$$

where

$$
\alpha^{*}=0,05+\gamma \leq 0,85
$$

\section{$\beta$ Parameter}

In following figures are represented the main results related to $\beta$ parameter. $\beta$ can be plotted as a function of transversal reinforcement spacing and of concrete strength. The numerical analysis show that $\beta$ is little sensitive to the lateral length tie.

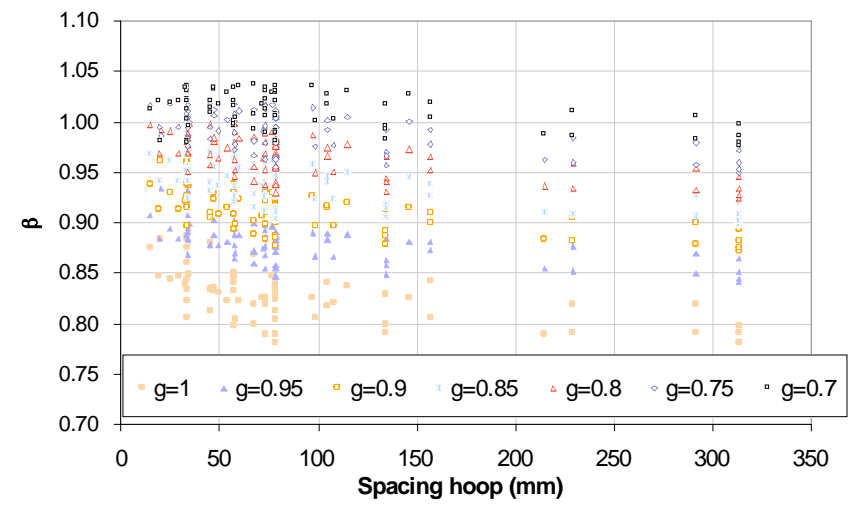

Fig. (25). Variation of $\beta$ parameter with spacing hoop for various $\gamma$ values $\left(\mathrm{f}_{\mathrm{c} 0}=20 \mathrm{MPa}\right)$.

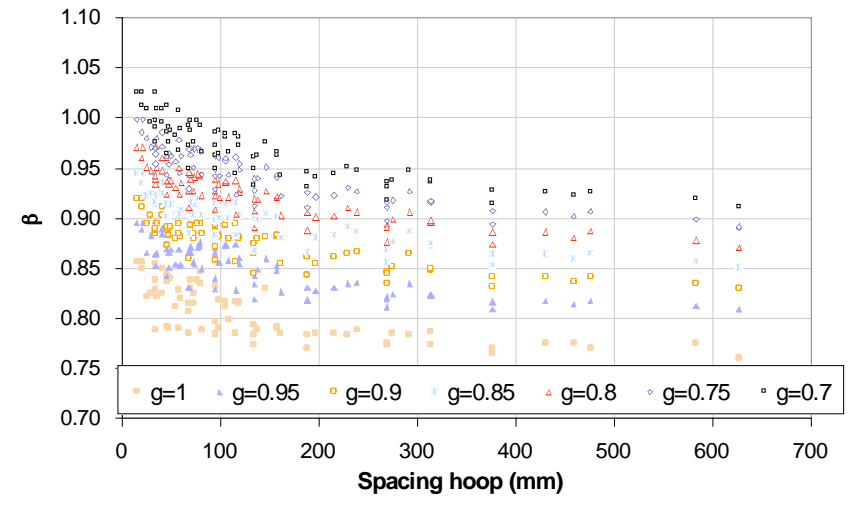

Fig. (26). Variation of $\beta$ parameter with spacing hoop for various $\gamma$ values $\left(\mathrm{f}_{\mathrm{c} 0}=30 \mathrm{MPa}\right)$.

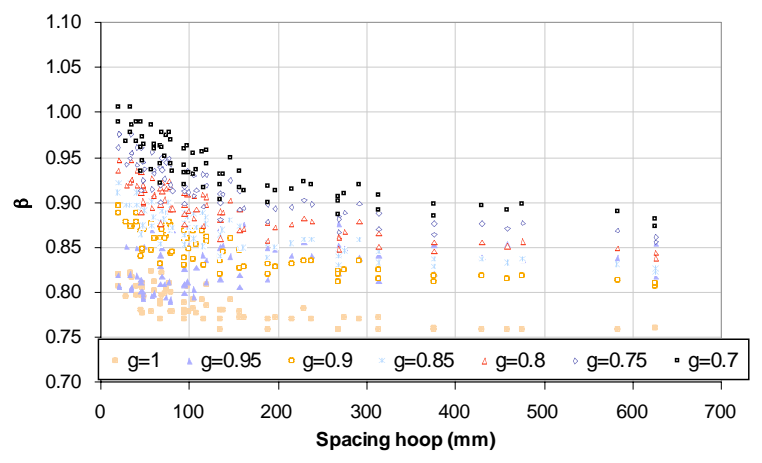

Fig. (27). Variation of $\beta$ parameter with spacing hoop for various $\gamma$ values $\left(\mathrm{f}_{\mathrm{c} 0}=40 \mathrm{MPa}\right)$.

In Figs. (28-30) are plotted $\beta$ values for three $f_{\text {co }}$ considered, fixing $\gamma$.

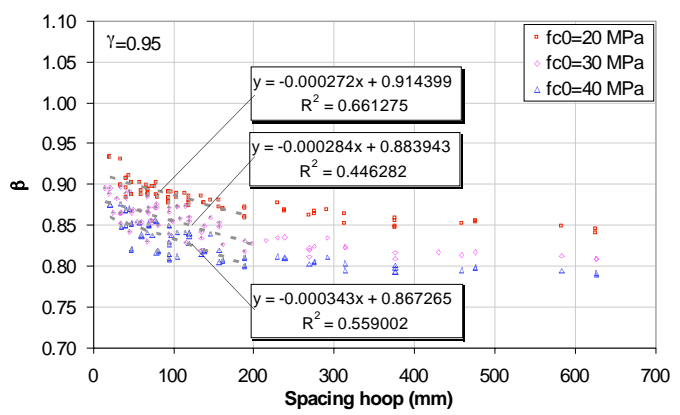

Fig. (28). Variation of $\beta$ parameter with spacing hoop for various $\mathrm{f}_{\mathrm{c} 0}$ values $(\gamma=0.95)$.

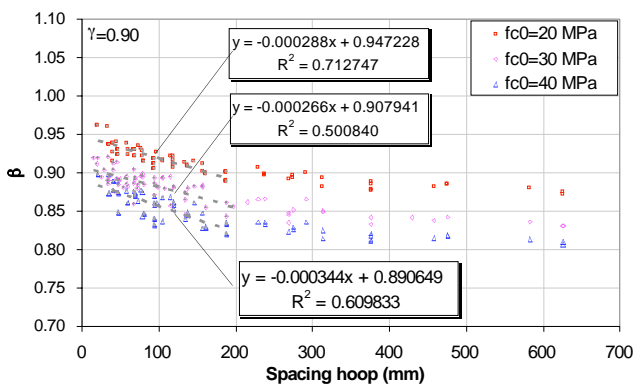

Fig. (29). Variation of $\beta$ parameter with spacing hoop for various $f_{c 0}$ values $(\gamma=0.90)$.

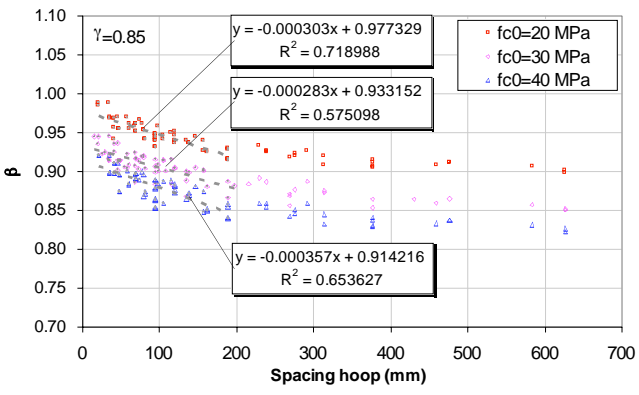

Fig. (30). Variation of $\beta$ parameter with spacing hoop for various $f_{c 0}$ values $(\gamma=0.85)$.

In Figs. (31-33) $\beta$ is plotted as a function of unconfined concrete strength for some values of $\gamma$. 


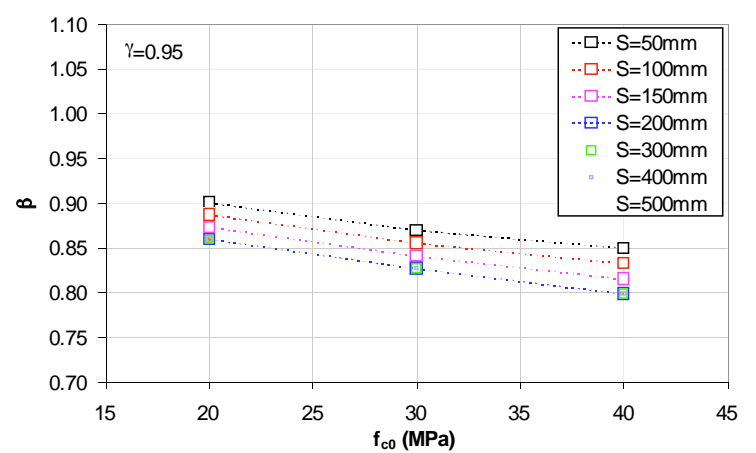

Fig. (31). Variation of $\beta$ parameter with unconfined concrete strength $\mathrm{f}_{\mathrm{c} 0}(\gamma=0.95)$.

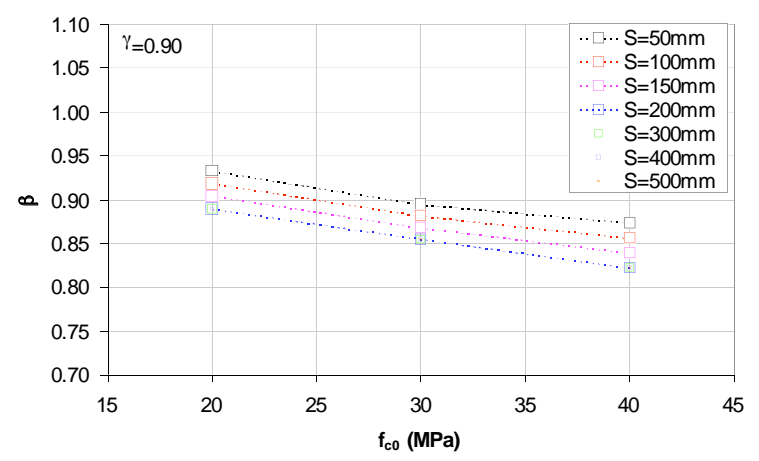

Fig. (32). Variation of $\beta$ parameter with unconfined concrete strength $\mathrm{f}_{\mathrm{c} 0}(\gamma=0.90)$.

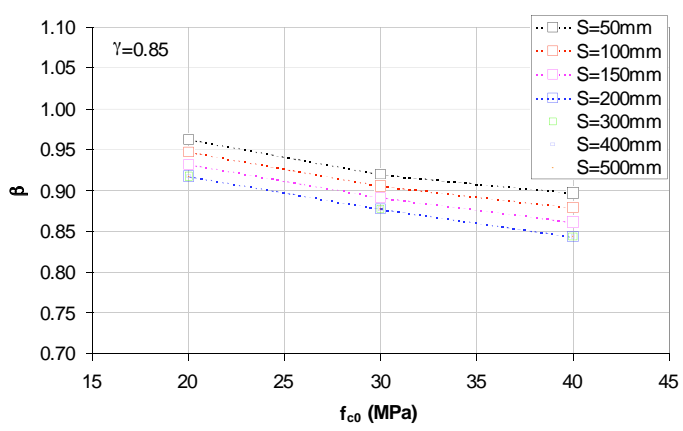

Fig. (33). Variation of $\beta$ parameter with unconfined concrete strength $\mathrm{f}_{\mathrm{c} 0}(\gamma=0.85)$.

According to the obtained results $\beta$ parameter can be described as $\left(f_{c 0}\right.$ is in $\mathrm{MPa}$ and $S$ is in $\left.\mathrm{mm}\right)$ :

$\beta=a(\gamma)+b(\gamma) \cdot S+c(\gamma) \cdot f_{c 0}$

where for a, b, c parameters can be adopted the following expressions:

$$
\left.\begin{array}{l}
a=-0.66 \cdot \gamma+1.59 \\
b=-0.0035 \cdot \gamma^{2}+0.0062 \cdot \gamma-0.003 \\
c=0.028 \cdot \gamma^{2}-0.0043 \cdot \gamma+0.013
\end{array}\right\}
$$

\section{Strength of Confined Concrete $f_{c c}\left(k_{s}\right.$ Parameter)}

As Figs. (34-37) show, the confined concrete strength $f_{c c}$ is a linear function of $\omega_{\mathrm{wd}}$ and is nearly independent both transversal spacing $S$ and unconfined concrete strength $f_{c 0}$ (unless S5 transversal reinforcement type).

Referring to $\mathrm{k}_{\mathrm{s}}$ parameter, $\mathrm{f}_{\mathrm{cc}}$ can be expressed by the following expression:

$$
\left.\begin{array}{l}
k_{s}=\frac{f_{c c}}{f_{c 0}}=1+\left(\rho-\rho_{0}\right) \cdot \xi_{S}\left(f_{c 0}\right) \\
\rho_{0}=0,0025 \\
\xi_{S 1}=-11,79 \cdot \frac{f_{c 0}}{20}+43,19 \\
\xi_{S 3}=-12,93 \cdot \frac{f_{c 0}}{20}+48,78 \\
\xi_{S 4-1}=-2,67 \cdot \frac{f_{c 0}}{20}+10,56 \\
\xi_{S 4-2}=-10 \cdot \frac{f_{c 0}}{20}+32,07
\end{array}\right\}
$$

For $\mathrm{S} 5$ section $\mathrm{f}_{\mathrm{cc}}$ is a function of lateral length tie, too.

$$
\xi_{S 5}=-8,5 \cdot \frac{f_{c 0}}{20}+b(L)
$$

where

$b(L)=-11 \cdot \frac{L}{300}+53,56$

In the previous expressions $\mathrm{f}_{\mathrm{c} 0}$ is in $\mathrm{MPa}$ and $\mathrm{L}$ is in $\mathrm{mm}$.

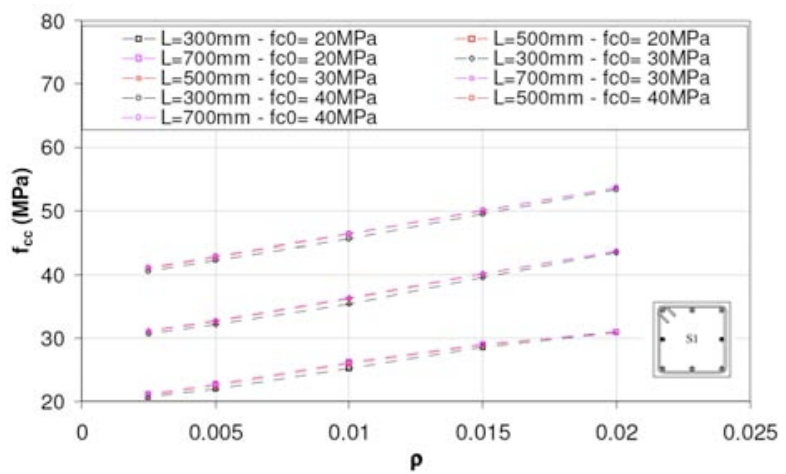

Fig. (34). S1 section type. Variation of strength of confined concrete with $\rho_{\mathrm{s}}$

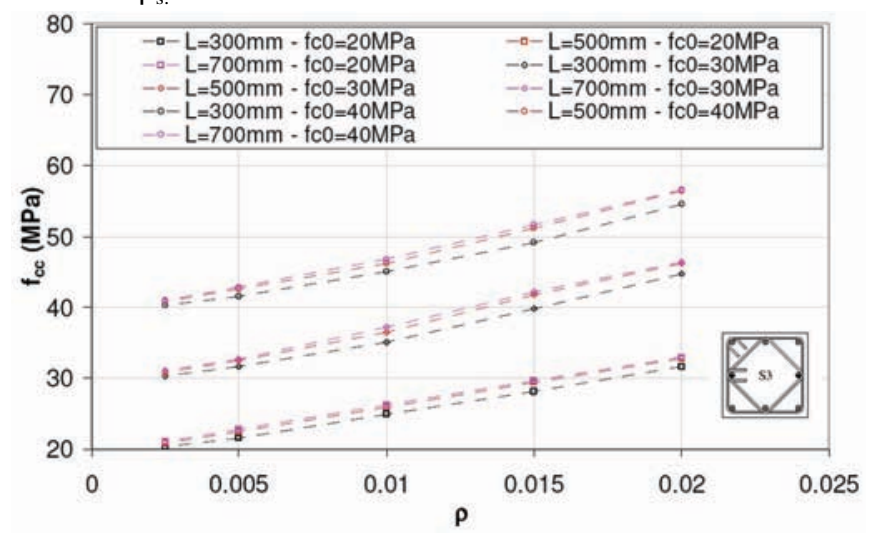

Fig. (35). S3 section type. Variation of strength of confined concrete with $\rho_{\mathrm{s}}$ 


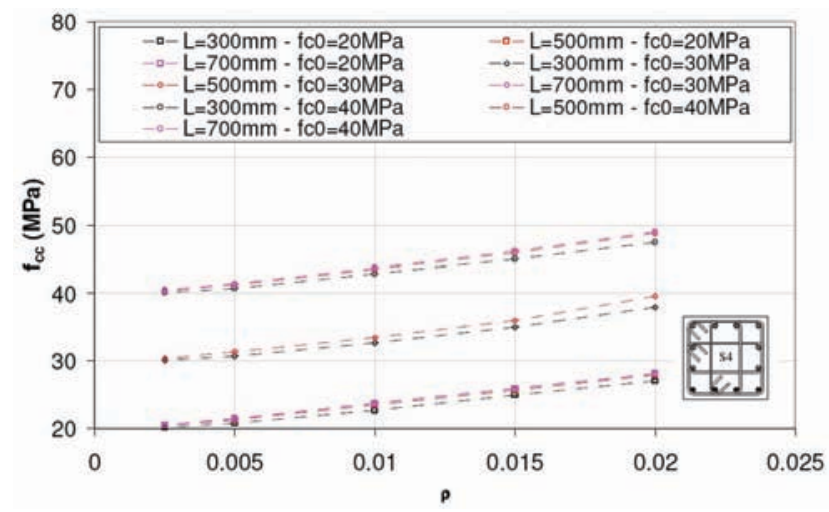

Fig. (36). S4 section type. Variation of strength of confined concrete with $\rho_{\mathrm{s}}$.

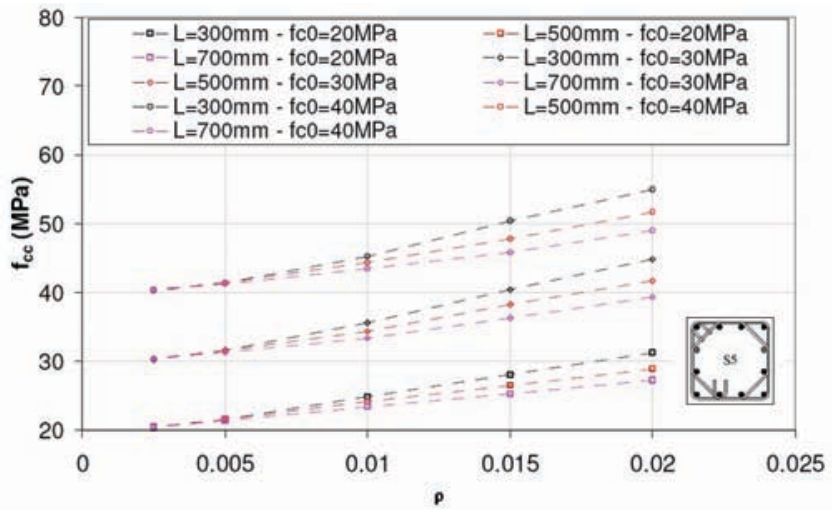

Fig. (37). S5 section type. Variation of strength of confined concrete with $\rho_{\mathrm{s}}$.

\section{CONCLUSIONS}

It has been studied the behaviour of RC sections with flexure and axial load considering the confinement effects.

Utilizing the analytical model for confined concrete proposed by Braga, Gigliotti and Laterza [10], it has been carried out analytical analysis according to the classic section methods.

The analysis done put on evidence the importance of the maximum concrete strain to utilize for evaluating the interaction curves of section. This strain depends either on the concrete strength or the confining level inside the section. It has been also deduced that the only one parameter $\rho$ is not enough useful to describe the confining state along the member.

Varying the maximum concrete strain it is possible to calculate the section strength in different limit states. For example it can be defined the maximum concrete strain guaranteeing the concrete cover wholeness or the ultimate concrete strain to calculate the flexural section strength in the last state of collapse.

In this paper, a new analytical formulation of stress-block parameters for confined concrete is presented. The obtained equations, relating to the considered cases, are simple to use.

Later, these analytical evaluations can be enlarged to a wide range of cases in order to obtain mathematical equations of a more general value.

\section{REFERENCES}

[1] NZS 3101:1995, "Concrete Structures Standard-The Design of Concrete Structures", Part1 and Part2, Standards Association of New Zealand, Wellington.

[2] Eurocode 8, "Design of Structures for Earthquake Resistance", CEN, 2003.

[3] Eurocode 2, "Design of Concrete Structures", CEN, 2003.

[4] ACI Committee 318, "Building Code Requirements for Structural Concrete and Commentary", American Concrete Institute, 2005.

[5] NZS 4203: 1994, "Code of Practice for General Structural Design and Design Loadings for Buildings". Standards Association of New Zealand, Wellington.

[6] Decreto Ministeriale 14 settembre 2005. "Norme Tecniche per le Costruzioni, Rome", Italy.

[7] CSA A23.3 1994 and CSA S6 2001, Design of Concrete Structures, Canadian Standards Association, Rexdale, Ontario, 1994.

[8]. The norvegian council for building standardization, "Norvegian Standard for Design of Concrete Structures", Oslo, Norway, 1995

[9] CEB-FIB. Model code 1990. Thomas Telford Service Ltd., London for comitè Euro-International du Bèton, Lausanne, 1993.

[10] F. Braga, R. Gigliotti, M. Laterza, "Analytical stress-strain relationship for concrete confined by steel stirrups and/or FRP jackets", Journal of Structural Engineering ASCE, Vol. 132, No. 9, pp. 1402-16, 2006.

[11] Sheikh, S. A., \& Uzumeri, S.M., "Strength and Ductility of Tied Concrete Columns". Journal of the Structural Division, ASCE, 106 (5), 1079-1102, 1980.

[12] Park R. and Paulay T., Reinforced Concrete Structures, John Wiley, New York, 1975

[13] C. B. Evan and P. C. Michael. Response-2000. "Reinforced Concrete Sectional Analysis (ver. 1.0.5)". University of Toronto.

[14] S.A. Sheikh, C.C. Yeh, S. Khoury (1990). Concrete strength in tied columns - ACI Structural Journal, Vol. 87. Issue 4, 1990, 